\title{
Absorption Enhancer and Polymer (Vitamin E TPGS and PVP K29) by Solid Dispersion Improve Dissolution and Bioavailability of Eprosartan Mesylate
}

\author{
Jae Soon Ahn, ${ }^{a}$ Kang Min Kim, ${ }^{\dagger, a}$ Chan Young Ko, ${ }^{\ddagger}$ and Jae Seon Kang\$, \\ Department of Pharmacy, Kyunghee University, Seoul 130-701, Korea \\ ${ }^{\dagger}$ Center for R\&D, Hyundai Pharm, Seoul 153-023, Korea \\ Department of Pharmacy, Sungkyunkwan University, Suwon 440-746, Korea \\ ${ }^{\S}$ Department of Pharmacy, Kyungsung University, Busan 608-736, Korea. ${ }^{*}$ E-mail: jskang8551002@ks.ac.kr \\ Received March 2, 2011, Accepted March 22, 2011
}

\begin{abstract}
The aim of the present study was to improve the solubility and bioavailability of a poorly water-soluble drug in human body, using a solid dispersion technique (hot melt extrusion). The solid dispersion was prepared by cooling the hot melt of the drug in the carrier (Vitamin E TPGS and PVP). The dissolution rate of formulation 1 from a novel formulation prepared by solid dispersion technique was equal to release of formulation $6(40 \%$ of eprosartan mesylate is in contrast to teveten ${ }^{\mathbb{B}}$ ) within $60 \mathrm{~min}$ (Table 1). The oral bioavailability of new eprosartan mesylate tablet having vitamin E TPGS and PVP K29 was tested on rats and dogs. Of the absorption enhancer and polymer tested, vitamin E TPGS and PVP K29, resulted in the greatest increases of AUC in animals (about 2.5 -fold increase in rat and $\operatorname{dog}$ ). When eprosartan mesylate was mixed with the absorption enhancer and polymer in a ratio of 2.94:2:1, vitamin E TPGS and PVP K29 improved eprosartan mesylate bioavailability significantly compared with the conventional immediate release (IR) tablet Teveten ${ }^{\mathbb{R}}$ (formulation 7). These results show that solid dispersion using vitamin E TPGS and PVP K29 is a promising approach for developing eprosartan mesylate drug products.
\end{abstract}

Key Words : Eprosartan mesylate, Solid dispersion, Vitamin E TPGS, PVP K29, Bioavailability

\section{Introduction}

Eprosartan is a nonpeptide angiotensin II receptor antagonist approved in more than 20 countries (e.g. US, UK, Germany) for the treatment of patients with hypertension. The drug is orally active and has a distinct nonbiphenyl, nontetrazol chemical structure. ${ }^{1}$ Pharmacokinetic studies of eprosartan have been conducted in healthy volunteers, patients with hypertension and in special patient populations. Eprosartan plasma concentrations peak at 1 to 3 hours after an oral dose in the fasted state. ${ }^{2}$ Administering eprosartan with food delays absorption, and causes variable changes $(<25 \%)$ in Cmax and AUC values which do not appear clinically important. ${ }^{3}$ Plasma concentrations of eprosartan increase in a slightly less than dose-proportional manner over the 100 $\mathrm{mg}$ to $800 \mathrm{mg}$ dose range. ${ }^{4}$ The mean terminal elimination half-life of eprosartan following multiple oral doses of $600 \mathrm{mg}$ was approximately 20 hours. Absolute oral bioavailability was calculated to be approximately $13 \%$ in a study of 17 healthy volunteers who received the commercially available oral tablet as well as an intravenous formulation of eprosartan tract. ${ }^{3}$ The low oral bioavailability of eprosartan may be the result of incomplete absorption due the physico-chemical properties of the drug. Eprosartan exhibits pH-dependent aqueous solubility and lipophilicity which may result in variable absorption as the compound passes through the gastrointestinal tract. ${ }^{3}$ Because the variable and mean ab-

${ }^{\mathrm{a}}$ These authors contributed equally to this work. solute bioavailability of eprosartan is only $13 \%$, doses as high as $800 \mathrm{mg}$ per day may be required for an effective treatment of hypertension, congestive heart failure and renal failure. ${ }^{5}$ Additionally, since the commercial form of the drug is its mesylate salt, high dose tablets (e.g., $600 \mathrm{mg}$ tablets weigh $1,000 \mathrm{mg}$ ) may be difficult to swallow. The oral bioavailability of eprosartan is limited by the solubility, rather than the metabolism within cytochrome P450 in the liver. Therefore, there is a need for a formulation that enhances the bioavailability of eprosartan.

Vitamin E TPGS ( $d$-alpha-tocopheryl polyethylene glycol 1000 succinate) was developed in the 1950 s as a watersoluble form of vitamin E. Vitamin E TPGS is comprised of a hydrophilic polar (water-soluble) head and a lipophilic (water-insoluble) alkyl tail. Due to its surface active properties, it can be used as a solubilizer, an emulsifier, as well as a vehicle for lipid-based drug delivery formulations. Recently, Vitamin E TPGS has been described as an effective oral absorption enhancer for improving the bioavailability of poorly absorbed drugs. ${ }^{6}$ The TPGS has a melting point of approximately $38^{\circ} \mathrm{C}$ and its degradation temperature has been reported to be $199.3{ }^{\circ} \mathrm{C}$. These physical properties coupled with its chemical properties make TPGS a potential candidate for hot-melt extrusion applications. ${ }^{7}$

Numerous techniques have been used to improve the oral bioavailability of these drugs by enhancing their solubility in water and in biological fluids at physiological $\mathrm{pH}$. The most popular approaches are solid dispersion, complexation, prodrug, nano- and micro-emulsion, nanoparticles, crystal form 
and cosolvent method. Hot-melt extrusion has a number of advantages, mainly: (a) it is a non-solvent technology, therefore it is environmentally friendly and cost-effective; and (b) from a commercial point of view, hot-melt extrusion can be carried out as a continuous process, thereby allowing the efficient scale-up of production. ${ }^{8}$ Solid dispersions are able to produce a local increase in the solubility (within the solid solution), and as the carrier dissolves, the drug comes into close contact with the dissolution medium. ${ }^{9}$ As there was no reported study on the development of solid dispersion for eprosartan, we took the opportunity to explore the advantages of solid dispersion for this drug. One of these strategies includes the formulation of a solid dispersion, which is defined as a dispersion of one or more active ingredients in an inert carrier or matrix, prepared by the melting, solvent, or melting solvent method. ${ }^{10}$

In this study, we compare the relative bioavailability and pharmacokinetics of the newly developed eprosartan-loaded solid dispersions with Teveten ${ }^{\circledR}$ tablet for decreased eprosartan mesylate content.

\section{Experimental}

Chemicals. Eprosartan mesylate was purchased from the Hetero Pharmaceutical Co., Ltd. (Hyderabad, India). Teveten ${ }^{\circledR}$ tablets $(735.8 \mathrm{mg})$ were purchased from Solvay Pharma (Hannover, Germany). d-alpha-tocopheryl polyethylene glycol 1000 succinate (Vitamin E TPGS) was purchased from Isochem Co., Ltd. (Paris, France). Polyvinylpyrrolidone (PVP K29), Crospovidone and Magnesium stearate were provided by BASF Korea (Seoul, Korea). Mannitol (Pearlitol ${ }^{\circledR} 100$ $\mathrm{SD}$ ) was purchased from Roquette (Lestrem, France). MgAluminometasilicate (US2) was purchased from Wooshin Medics, Co., Ltd. (Seoul, Korea). All other chemicals were obtained from Sigma-Aldrich (St. Louis, MO, USA).

Solid Dispersion. Hot-melt extrusion method was modified from Zhang and McGinity, 1999; Zhang and McGinity, 2000. ${ }^{11,12}$ A physical blend of vitamin E TPGS and PVP K29 was prepared by mixing the powders in a suitable flask. The temperature was maintained at $50{ }^{\circ} \mathrm{C}$ with stirring to maintain a homogenous solution. Upon the subsequent addition of eprosartan mesylate to the solution, US2 was immediately mixed into a same flask with cool down to the temperature. A suspension was granulated by passing through a 35-mesh screen was immediately mixed into a same flask with cooling down (Table 1).

Formulation of Tablets. Direct compression method was used to prepare the tablet of eprosartan mesylate: A suspension as described above was diluted with Pearlitol ${ }^{\circledR}$ 100 SD. Crospovidone was used as superdistegrant agent. This mixture was lubricated using magnesium stearate and compressed on an IR press (Carver Laboratory Press FT15, Fred S. Carver, USA) (Table 1).

In vitro Dissolution Study of Tablet. A dissolution profile of a novel formulation was followed from Chiang, 2006. ${ }^{13}$ Dissolution profiles of tablets containing solid dispersion were determined at $37^{\circ} \mathrm{C}$, in $0.01 \mathrm{~N} \mathrm{HCl}$ buffer $(\mathrm{pH}$ 1.2) and $0.05 \mathrm{M} \mathrm{CH}_{3} \mathrm{COONa}$ buffer ( $\left.\mathrm{pH} 4.0\right)$, while in dissolution tester at $50 \mathrm{rpm}$ using the basket method according to Korea Pharmacopoeia (KP) dissolution procedure. In addition, the drug release profile from a marketed product, Teveten ${ }^{\circledR}$ tablets, was examined for comparison purposes. In each dissolution test, a weighed quantity of all formulations was placed in $900 \mathrm{~mL}$ of the dissolution medium. Each of the $1 \mathrm{~mL}$ aliquots was withdrawn at 5, 10, 15, 30 and $60 \mathrm{~min}$ through a filtering rod $(10 \mathrm{~mm})$. Filtered samples were assayed by a high pressure liquid chromatography (HPLC) method for eprosartan concentrations. The optimal conditions of eprosartan detection were achieved using an HPLC (Agilent Technologies, 1200 series, USA) column (X-Terra $\mathrm{RP} 18,150 \mathrm{~mm} \times 4.6 \mathrm{~mm}, 5 \mu \mathrm{m})$ and detection at $234 \mathrm{~nm}$ using a UV monitor (Agilent Technologies, 1200 series, Photo-Diode Array UV/vis detector, USA). The column was held at $30{ }^{\circ} \mathrm{C}$ and the mobile phase consisted of $0.4 \%$ Triethyl amine in water $(\mathrm{pH} 3.0$, using phosphoric acid solution) - acetonitrile (60:40, v/v). Chromatography was performed isocratically at a flow rate of $1 \mathrm{~mL} / \mathrm{min}$. Drug concentrations were expressed as the percentage of eprosartan

Table 1. Formulations of the eprosartan mesylate tablets

\begin{tabular}{|c|c|c|c|c|c|c|c|}
\hline & Formulation 1 & Formulation 2 & Formulation 3 & Formulation 4 & Formulation 5 & Formulation 6 & Formulation 7 \\
\hline Tablet components (mg) & & & & & & \multirow{8}{*}{$\begin{array}{c}294.3 \text { of } \\
\text { eprosartan } \\
\text { mesylate in } \\
\text { Teveten }^{\circledR}\end{array}$} & \multirow{8}{*}{$\begin{array}{c}735.8 \text { of } \\
\text { eprosartan } \\
\text { mesylate in } \\
\text { Teveten }^{\circledR}\end{array}$} \\
\hline Eprosartan mesylate & 294.3 & 441.5 & 515.1 & 588.6 & 735.8 & & \\
\hline Vitamin E TPGS & 200 & 200 & 200 & 200 & 200 & & \\
\hline PVP K29 & 100 & 100 & 100 & 100 & 100 & & \\
\hline US2 & 50 & 50 & 50 & 50 & 50 & & \\
\hline Pearlitol ${ }^{\circledR} 100$ SD & 445.7 & 298.5 & 224.9 & 151.4 & 304.2 & & \\
\hline Crospovidone & 70 & 70 & 70 & 70 & 70 & & \\
\hline Magnesium stearate & 40 & 40 & 40 & 40 & 40 & & \\
\hline Tablet weight (mg) & 1200 & 1200 & 1200 & 1200 & 1500 & - & - \\
\hline $\begin{array}{l}\text { Eprosartan mesylate content } \\
\text { in tablet }(\%)\end{array}$ & $40.8 \pm 0.1^{a}$ & $60.6 \pm 0.2^{b}$ & $71.3 \pm 0.1^{c}$ & $80.8 \pm 0.2^{d}$ & $101.3 \pm 0.2^{e}$ & $40.3 \pm 0.1^{f}$ & $100.6 \pm 0.2^{g}$ \\
\hline
\end{tabular}

${ }^{a}$ eprosartan mesylate is in contrast to Teveten ${ }^{\circledR} ; 40 \% .{ }^{b}$ eprosartan mesylate is in contrast to Teveten ${ }^{\circledR} ; 60 \%$. ${ }^{c}$ eprosartan mesylate is in contrast to Teveten $^{\circledR} ; 70 \%$. ${ }^{d}$ eprosartan mesylate is in contrast to Teveten ${ }^{\mathbb{Q}} ; 80 \%$. ${ }^{e}$ eprosartan mesylate equal to Teveten ${ }^{\circledR} ; 100 \%$. ${ }^{f_{2}} 294.3$ mg of eprosartan mesylate in Teveten ${ }^{\mathbb{Q}} ; 40 \%$. ${ }^{g} 735.8 \mathrm{mg}$ of eprosartan mesylate in Teveten ${ }^{\circledR} ; 100 \%$. 
mesylate released over time ( $n=6$ each).

In vivo Experiments for Administration and Bloodcollecting. Male SD rats $(240.3 \pm 11.2 \mathrm{~g})$ and beagle dogs $(14.6 \pm 0.6 \mathrm{~kg})$ were used in the pharmacokinetic studies, and all animals were treated in accordance with guidelines offered by Guide for the Care and Use of Laboratory Animals from the National Institutes of Health. Prior to each experiment, the animals were fasted overnight with free access to water. All animals were kept in a temperaturecontrolled environment $\left(23 \pm 2^{\circ} \mathrm{C}\right)$ with a $12 \mathrm{~h}$ light-dark cycle. Food and water were freely available. Six rats were divided into two groups. For oral administration, 40, 60, 70 and $80 \%$ of eprosartan mesylate in contrast to Teveten ${ }^{\circledR}$ (formulation 1, 2, 3 and 4) in novel formulations and Teveten $^{\circledR}$ (formulation 7) were suspended in distilled water at a concentration of $12.3 \mathrm{mg} / \mathrm{kg}$ body weight (Table 1). Six male beagle dogs were used where one tablet per dog was administered. According to a randomized crossover, each dog received prepared batches of either formulation 1 in a novel formulation or Teveten ${ }^{\mathbb{B}}$ (formulation 7) with a washout period of 1 week (Table 1).

For evaluation of the eprosartan following oral administration of rats, blood samples $(1 \mathrm{~mL})$ were collected from a retroorbital immediately before administration, and at $0.5,1,2$ and $4 \mathrm{~h}$ after administration. For evaluation of the eprosartan following oral administration of beagle dogs, legs were shaven and blood samples were collected from the cephalic vein. Blood samples $(1 \mathrm{~mL})$ were collected immediately before administration and at $0.25,0.5,1,2,4,6,8,12$ and $24 \mathrm{~h}$ after administration. All heparinized blood samples were immediately cooled on ice and then centrifuged at 3,000 rpm $\left(4^{\circ} \mathrm{C}\right)$ for $15 \mathrm{~min}$. The plasma was stored at $-70^{\circ} \mathrm{C}$ until analysis was performed.

Plasma Sample Preparation. One hundred microliters of plasma samples were added into microcentrifuge tubes. To each sample, $10 \mu \mathrm{L}$ of internal standard solution $(500 \mathrm{ng} / \mathrm{mL})$ was added, as well as $1 \mathrm{~mL}$ ethyl acetate. Then the tubes were capped and vortexed for $10 \mathrm{~s}$. Samples were centrifuged at $3,000 \mathrm{rpm}$ and $-4^{\circ} \mathrm{C}$ for $10 \mathrm{~min}$. The upper organic layer (ethyl acetate layer of $900 \mu \mathrm{L}$ ) was transferred into another microcentrifuge tube and completely evaporated at $40^{\circ} \mathrm{C}$. The dry residue was then reconstituted with $200 \mu \mathrm{L}$ methanol and injected into the LC-MS/MS for mass spectral analysis.

Eprosartan Mesylate Standard, QC and IS Preparation. Primary stock solution of eprosartan mesylate $(1 \mathrm{mg} / \mathrm{mL})$ and Chlorhexidine [Internal standard (IS); $500 \mu \mathrm{g} / \mathrm{mL}$ ] were prepared in $80 \% \mathrm{MeOH}$. Working standard solutions of eprosartan mesylate were prepared by combining aliquots of primary stock solution and diluting with $80 \% \mathrm{MeOH}$. The working solution for the internal standard $(500 \mathrm{ng} / \mathrm{mL})$ was prepared by diluting with $80 \% \mathrm{MeOH}$. Plasma calibration standards of eprosartan mesylate at eight concentrations (1, $10,50,100,200,500$ and $1000 \mathrm{ng} / \mathrm{mL}$ ) were prepared and analyzed by spiking the working standard solutions. For the plasma quality control (QC) samples, $10 \mu \mathrm{L}$ of the QC working solution $(10,500,5,000$ and $10,000 \mathrm{ng} / \mathrm{mL})$ was added to microcentrifuge tubes containing $90 \mu \mathrm{L}$ control plasma to yield final QC concentrations of 1, 50, 500 and $1,000 \mathrm{ng} / \mathrm{mL}$ ). QCs were stored at $-20^{\circ} \mathrm{C}$.

Extraction Recovery and Stability. The recovery of eprosartan mesylate was determined by comparing the peak area obtained for QC samples $(1,50,500$ and $5000 \mathrm{ng} / \mathrm{mL})$. All samples were followed by Li et al., 2007 for the stability of eprosartan mesylate. ${ }^{14}$

LC-MS/MS Conditions. Tandem mass spectrometry (MS/ MS) was performed using a Sciex API 2000 triple quadruple mass spectrometer equipped with turbo electrospray ion source (Foster City, CA USA). The conditions were modified from the method described by Kim et al., 2003; Wen et al., $2008 .^{15,16}$ Ten microliters of sample were delivered into the ESI source using the micro-LC (Foster City, CA USA) and autosampler (Agilent Technologies, 1200 series, USA) with zorbox eclipse XDB-C18 column $(2.1 \times 50 \mathrm{~mm}, 5 \mu \mathrm{m}$ particle size). The isocratic mobile used after degassing was composed of $10 \%$ solvent A $(0.1 \%$ formic acid in water) and $90 \%$ solvent B $(0.1 \%$ formic acid in acetonitrile), with a total running time of $2 \mathrm{~min}$ and flow rate of $300 \mu \mathrm{L} / \mathrm{min}$. In detecting eprosartan using the multiple reaction monitoring (MRM) scan mode with positive ion detection, the following parameter settings were used: declustering potential (DP), $151 \mathrm{~V}$; collision energy (CE), $73 \mathrm{eV}$; focusing potential (FP), $340 \mathrm{~V}$; collision cell exit potential (CXP), $2 \mathrm{~V}$; spray voltage, $5500 \mathrm{~V}$; and ion temperature, $450^{\circ} \mathrm{C}$. Ion source gas 1 (GS1), Ion source gas 2 (GS2), curtain gas (CUR) and collision gas (CAD) were 40, 75, 20 and 6 psi, respectively. The monitoring ions were set as $\mathrm{m} / \mathrm{z} 425.2 \rightarrow 107.1$ for eprosartan and $\mathrm{m} / \mathrm{z} 506.4 \rightarrow 368.3$ for Chlorhexidine. The scan dwell time was set at $150 \mathrm{~ms}$ for every channel.

\section{Results and Discussion}

In vitro Dissolution Studies. To test whether eprosartan mesylate or not affect the dissolution rates of drug from the vitamin E TPGS and PVP K29 tablets, we performed the dissolution tests of the formulation 5 and Teveten ${ }^{\circledR}$ (formulation 7) tablets. Eprosartan mesylate was found to be stable under the current condition. There was no change in the retention time after the extrusion process. The profile in Figure 1 demonstrates that drug release was significantly increased to depend on vitamin E TPGS and PVP K29 when dissolution of Teveten ${ }^{\circledR}$ (formulation 7) was compared with formulation 5 having differentiated ingreadients under the same eprosartan mesylate. The release rates of eprosartan mesylate were influenced by the presence of vitamin E TPGS and PVP K29 according to the amount of Pearlitol ${ }^{\circledR} 100$ SD (Fig. 1(a)). According to increased results of dissolution in $\mathrm{pH} 1.2$, dissolution in $\mathrm{pH} 4.0$ of eprosartan mesylate also increased (Fig. 1(b)).

In the absence of vitamin E TPGS and PVP K29, as the ratio of vitamin E TPGS and PVP K29 to eprosartan mesylate from 2.94:2:1 (formulation 1), the high solubility of eprosartan mesylate in $\mathrm{pH} 1.2$ increased. However, as the other increased ratio of eprosartan mesylate (formulation 2, 3,4 , and 6) under the fixed total volume, the solubility of 

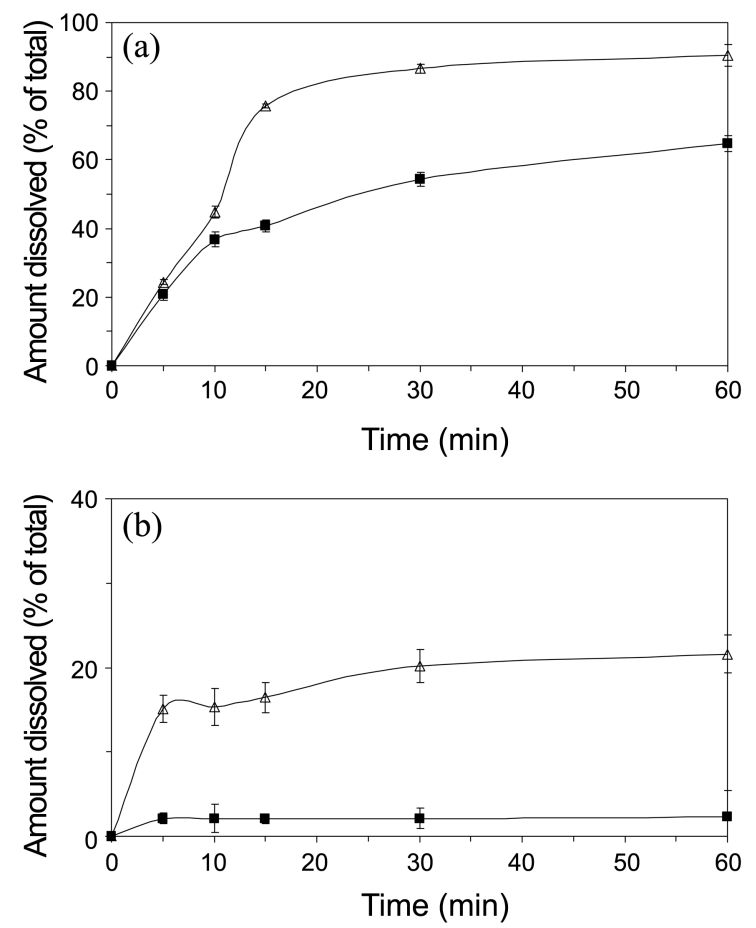

Figure 1. Dissolution profiles of the tablets, treated in (A) $\mathrm{pH} 1.2$ and (B) $\mathrm{pH}$ 4.0. $\triangle$, Formulation 5; $\mathbf{\square}$, Formulation 7 (mean \pm S.D., $n=8)$.

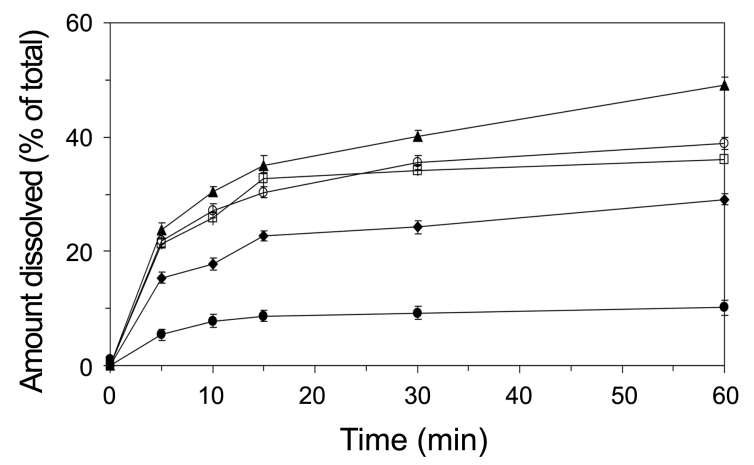

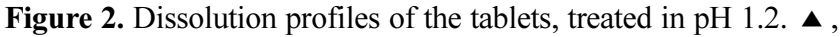
Formulation $1 ; \square$, Formulation 2 ; $\diamond$, Formulation 3 ; $\boldsymbol{\bullet}$, Formulation 4; $\bigcirc$, Formulation 6 (mean \pm S.D., $n=8)$.

eprosartan mesylate in $\mathrm{pH} 1.2$ decreased (Fig. 2). These results appeared to different aspects of dissolution depend on the amount of Pearlitol ${ }^{\circledR} 100$ SD.

Standard Curve. The retention time of eprosartan mesylate and IS of MS/MS was about 0.48 and 0.79 min, respectively. Standard calibration curves were constructed on different working days using the same dog plasma. A validation was performed to assess the performance of the method. Sevenpoint calibration standard curve of eprosartan ranging from 1 to $1,000 \mathrm{ng} / \mathrm{mL}$ in dog plasma was used in triplicate in each analytical run. For eprosartan, the regression equation was $\mathrm{y}=0.0323 \mathrm{x}-0.0292(r=0.9997, n=5)$ over the range of $1-1,000 \mathrm{ng} / \mathrm{mL}$. Thus, the calibration curve did not exhibit any non-linearity within the chosen range. The lower limit of quantification (LLOQ) of eprosartan was established at $1 \mathrm{ng} /$
Table 2. Intra- and inter- day accuracy and precision of eprosartan in dog plasma

\begin{tabular}{|c|c|c|c|c|}
\hline & $\begin{array}{c}\text { Low } \\
(1 \mathrm{ng} / \mathrm{mL})\end{array}$ & $\begin{array}{c}\text { Low } \\
(50 \mathrm{ng} / \mathrm{mL})\end{array}$ & $\begin{array}{c}\text { Middle } \\
(500 \mathrm{ng} / \mathrm{mL})\end{array}$ & $\begin{array}{c}\text { High } \\
(5,000 \mathrm{ng} / \mathrm{mL})\end{array}$ \\
\hline \multicolumn{5}{|c|}{ Intra-day accuracy and precision } \\
\hline Mean & 1.02 & 49.63 & 499.60 & 1004.63 \\
\hline S.D. & 0.05 & 0.76 & 3.76 & 7.02 \\
\hline$\% \mathrm{CV}$ & 4.41 & 1.54 & 0.75 & 0.70 \\
\hline$\%$ Deviation & 0.59 & 0.39 & 0.30 & 0.31 \\
\hline$n$ & 5 & 5 & 5 & 5 \\
\hline \multicolumn{5}{|c|}{ Inter-day accuracy and precision } \\
\hline Mean & 1.03 & 50.20 & 501.56 & 997.17 \\
\hline S.D. & 0.07 & 1.05 & 3.52 & 4.13 \\
\hline$\% \mathrm{CV}$ & 6.80 & 2.10 & 0.70 & 0.41 \\
\hline$\%$ Deviation & 0.60 & 0.64 & 0.31 & 0.29 \\
\hline$n$ & 5 & 5 & 5 & 5 \\
\hline
\end{tabular}

$\mathrm{mL}$, and the coefficient of variation (CV) was less than $20 \%$. Based on the standard data presented here, it was concluded that the calibration curves used in this method were precise and accurate for the measurement of eprosartan in dog plasma.

Accuracy and Precision. The intra- and inter-day accuracy and precision of the assay were characterized by the four levels of QCs run in five replicates. The results, which were summarized in Table 2, demonstrated that the accuracy and precision values were within the acceptable range and the method was accurate and precise. Accuracy was assessed by calculating the percent deviation from the theoretical concentration. Precision was determined by calculating the coefficient of variation for intra- and inter-day replicates.

Extraction Recovery. The extraction recoveries of eprosartan were $91.3 \pm 1.6 \%, 90.6 \pm 2.3 \%, 91.9 \pm 2.9 \%$ and $92.1 \pm 1.7 \%$ at the concentrations of $1,50,500$ and $1000 \mathrm{ng} /$ $\mathrm{mL}$, respectively (data not shown). The sensitivity is good enough for the detection of the drug concentration

Pharmacokinetic Study. The pharmacokinetic parameters of novel formulations in eprosartan mesylate were determined after oral administration of formulation 1,2,3, 4, and Teveten $^{\circledR}$ (formulation 7), respectively. Formulation 1, 2, 3, 4 , and Teveten ${ }^{\circledR}$ (formulation 7) were tested firstly for bio-

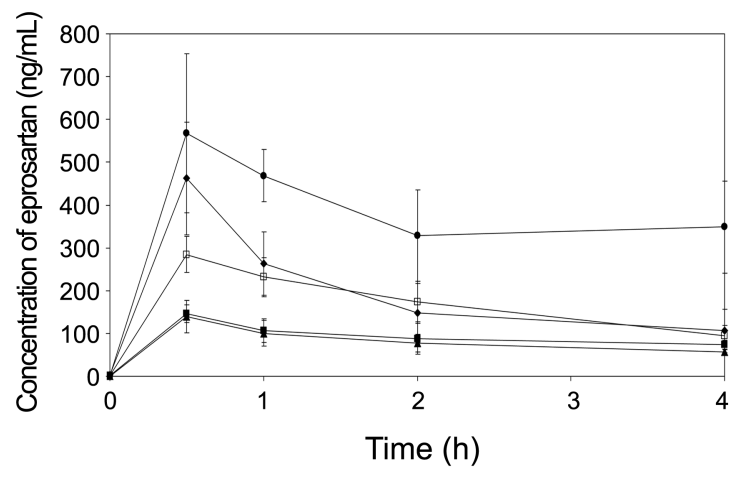

Figure 3. Plasma concentration of eprosartan in rats plasma time curve (mean \pm S.E., $n=10$ ). $\boldsymbol{\Delta}$, Formulation 1; $\square$, Formulation 2; $\diamond$, Formulation 3; •, Formulation 4; $\mathbf{\square}$, Formulation 7. 
Table 3. Pharmacokinetics of eprosartan in novel formulations and Teveten ${ }^{\circledR}$ in rats (mean \pm S.E., $\left.n=10\right)$

\begin{tabular}{lccccc}
\hline \multicolumn{1}{c}{ Parameters } & Formulation 1 & Formulation 2 & Formulation 3 & Formulation 4 & Formulation 7 \\
\hline$C_{\max }(\mathrm{ng} / \mathrm{mL})$ & $147.7 \pm 25.52$ & $315.67 \pm 52.93$ & $462.00 \pm 79.81$ & $725.83 \pm 113.62$ & $168.37 \pm 20.31$ \\
$T_{\max }(\mathrm{h})$ & $0.6 \pm 0.1$ & $0.5 \pm 0.1$ & $0.5 \pm 0.1$ & $0.5 \pm 0.1$ & $0.6 \pm 0.1$ \\
MRT $(\mathrm{h})$ & $1.62 \pm 0.2$ & $1.67 \pm 0.1$ & $1.52 \pm 0.2$ & $1.87 \pm 0.1$ & $1.53 \pm 0.1$ \\
$t_{1 / 2}(\mathrm{~h})$ & $1.05 \pm 0.2$ & $1.01 \pm 0.2$ & $0.99 \pm 0.1$ & $1.05 \pm 0.2$ & $1.04 \pm 0.2$ \\
$\mathrm{AUC}_{(0-4)}(\mathrm{hng} / \mathrm{mL})$ & $357.93 \pm 61.57$ & $672.77 \pm 99.61$ & $756.75 \pm 101.32$ & $1476.93 \pm 397.89$ & $327.15 \pm 55.36$ \\
$\mathrm{AUC}_{(0-\infty)}(\mathrm{hng} / \mathrm{mL})$ & $383.29 \pm 89.65$ & $816.78 \pm 102.38$ & $945.53 \pm 129.72$ & $1869.93 \pm 501.31$ & $371.23 \pm 90.61$ \\
\hline
\end{tabular}

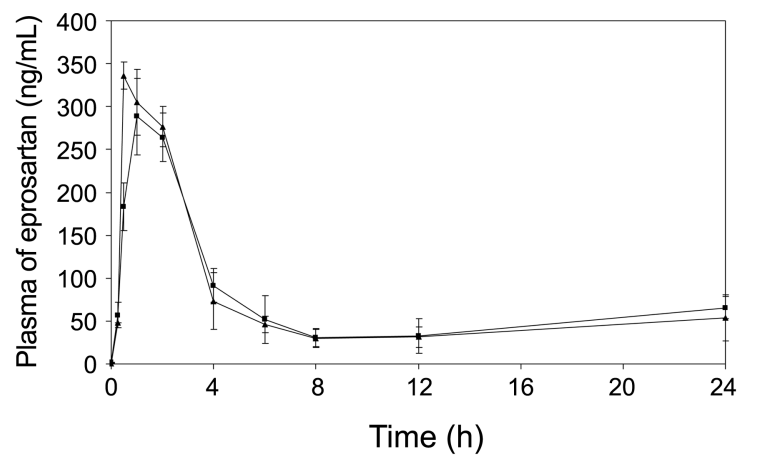

Figure 4. Plasma concentration of eprosartan in dogs plasma time curve (mean \pm S.E., $n=12$ ). $\mathbf{\Delta}$, Formulation 1 ; $\mathbf{\square}$, Formulation 7.

availability in rats. There have the volume of differentiated eprosartan mesylate and Pearlitol ${ }^{\circledR} 100$ SD under the volume of fixed vitamin E TPGS and PVP K29. Figure 3 and Figure 4 represented the change of mean plasma concentration of eprosartan after oral administration in rats and dogs. There are all values of parameters in Table 3 and 4. Formulation 1 and 7 were similar to the maximum plasma concentration $\left(C_{\max }\right)$, the time to maximum plasma concentration $\left(T_{\max }\right)$, the mean residence time (MRT), elimination half-life $\left(t_{1 / 2}\right)$, $\mathrm{AUC}_{(0-4)}$ (the area under the plasma concentration-time curve from 0 to $4 \mathrm{~h}$ ) and $\mathrm{AUC}_{(0-\infty)}$ (the area under the plasma concentration-time curve from 0 to infinity) in rats (Table 3 ). According to results of $\mathrm{pK}$ parameters in rats, formulation 1 having similar $\mathrm{pK}$ parameters of Teveten ${ }^{\circledR}$ (formulation 7) and formulation 7 were determined to indentify $\mathrm{pK}$ parameters in dogs (Table 4). These results indicated that the decreased eprosartan mesylate from vitamin E TPGS and PVP K29 were better absorbed in relation to Teveten ${ }^{\circledR}$ in rats and dogs. In particular, in vitamin E TPGS and PVP K29, the plasma concentrations of eprosartan were significantly differed according to content of eprosartan mesylate and

Table 4. Pharmacokinetics of eprosartan in novel formulations and Teveten ${ }^{\circledR}$ in dogs (mean \pm S.E., $n=12$ )

\begin{tabular}{lcc}
\hline \multicolumn{1}{c}{ Parameters } & Formulation 1 & Formulation 7 \\
\hline$C_{\max }(\mathrm{ng} / \mathrm{mL})$ & $476.56 \pm 125.51$ & $465.63 \pm 133.86$ \\
$T_{\max }(\mathrm{h})$ & $1.13 \pm 0.18$ & $1.25 \pm 0.72$ \\
$\mathrm{MRT}(\mathrm{h})$ & $11.05 \pm 2.10$ & $10.86 \pm 2.19$ \\
$t_{1 / 2}(\mathrm{~h})$ & $0.96 \pm 0.2$ & $1.14 \pm 0.23$ \\
$\mathrm{AUC}_{(0-24)}(\mathrm{hng} / \mathrm{mL})$ & $2381.32 \pm 367.98$ & $2221.92 \pm 351.79$ \\
$\mathrm{AUC}_{(0-\infty)}(\mathrm{hng} / \mathrm{mL})$ & $2633.98 \pm 416.46$ & $2442.77 \pm 392.41$ \\
\hline
\end{tabular}

Pearlitol $^{\circledR} 100$ SD (Figs. 3 and 4). The reason for this improved absorption might be attributed to the permeationenhancing effect of vitamin E TPGS and PVP K29 as other compounds. ${ }^{17,18}$ In other words, these results also suggested that vitamin E TPGS and PVP K29 would be useful to deliver eprosartan mesylate in a pattern that allows improved absorption, leading to better absorption. We demonstrated the potential of vitamin E TPGS and PVP K29 tablet processed by hot-melt extrusion for improving oral delivery. Our results also indicate that the proposed method has been successfully applied to pharmacokinetic studies to determine the concentration of eprosartan in human plasma.

\section{Conclusions}

From these observations of improved dissolution and pharmacokinetic behaviors, the vitamin E TPGS and PVP K29 tablet could be efficacious in enhancing the bioavailability of pharmacokinetic behaviors in animals. According to the pharmacokinetic profiles of vitamin E TPGS and PVP K29 tablet, there was significant improvement in permeation enhancer system with increase in $C_{\max }$ and AUC. In addition, Vitamin E TPGS and PVP K29 tablet for eprosartan mesylate provided in the present invention enhance the oral absorption of eprosartan mesylate by increasing the solubility of eprosartan mesylate in the gastrointestinal fluids. These results will be useful for further pharmacokinetic studies of eprosartan mesylate during clinical trial.

Acknowledgments. This research was supported by a Kyungsung University Research Grant in 2011.

\section{References}

1. Plosker, G. L.; Foster, R. H. Drugs 2003, 60, 177.

2. McClellan, K. J.; Balfour, J. A. Drugs 1998, 55, 713.

3. Tenero, D.; Martin, D.; Ilson, B.; Jushchyshyn, J.; Boike, S.; Lundberg, D.; Zariffa, N.; Boyle, D.; Jorkasky, D. Biopharm. Drug. Dispos. 1998, 19, 351.

4. Chapelsky, M. C.; Martin, D. E.; Tenero, D. M.; Ilson, B. E.; Boike, S. C.; Etheredge, R.; Jorkasky, D. K. J. Clin. Pharmacol. 1998, 38, 34 .

5. Hedner, T.; Himmelmann, A. Am. J. Hypertens. 1997, 10, 119A.

6. Collnot, E. M.; Baldes, C.; Wempe, M. F.; Hyatt, J.; Navarro, L.; Edgar, K. J.; Schaefer, U. F.; Lehr, C. M. J. Control. Release. 2006, 111,35 .

7. Repka, M. A.; McGinity, J. W. Int. J. Pharm. 2000, 202, 63.

8. Chokshi, R. J.; Sandhu, H.; Iyer, R. M.; Shah, N. H.; Malick, A. W.; Zia, H. J. Pharm. Sci. 2005, 11, 2463. 
9. Leuner, C.; Dressman, J. Eur. J. Pharm. Biopharm. 2000, 50, 47.

10. Chiou, W. L.; Riegelman, S. J. Pharm. Sci. 1971, 60, 1281.

11. Zhang, F.; McGinity, J. W. Pharm. Dev. Technol. 1999, 4, 241.

12. Zhang, F.; McGinity, J. W. Drug Develop. Ind. Pharm. 2000, 26, 931.

13. Ching, C. C. 2006, PCT patent 052461.

14. Li, X. N.; Xu, H. R.; Chen, W. L.; Liu, G. Y.; Chu, N. N.; Yu, C. J. Chrom. B 2007, 853, 47.
15. Kim, H.; Yoo, J. Y.; Han, S. B.; Lee, H. J.; Lee, K. R. J. Pharm. Biomed. Anal. 2003, 32, 209.

16. Wen, A.; Hang, T.; Chen, S.; Wang, Z.; Ding, L.; Tian, Y.; Zhang, M.; Xu, X. J. Pharm. Biomed. Anal. 2008, 48, 829.

17. Li, C. J.; Higashiyama, K.; Yoshimura, Y.; Nagai, T.; Takayama, K.; Obata, Y. Biol. Pharm. Bull. 2001, 24, 1044.

18. Obata, Y.; Sato, H.; Li, C. J.; Takayama, K.; Higashiyama, K.; Nagai, T.; Isowa, K. Int. J. Pharm. 2000, 198, 191. 